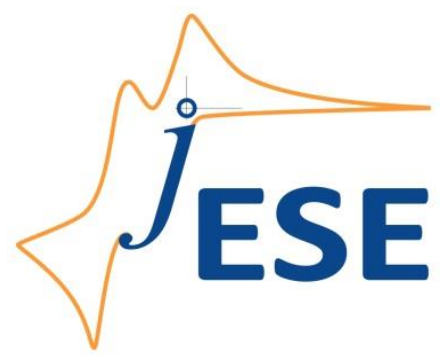

Open Access : : ISSN 1847-9286

www.jESE-online.org

Original scientific paper

\title{
Etoricoxib selective sensor based on uracil-5,6-diamino-2-thio hydrochloride as neutral carrier for potentiometric analysis in pharmaceutical preparations
}

\author{
Salwa Fares Rassi ${ }^{凶}$ \\ Department of Chemistry, Faculty of Science, Al-Baath University, Homs, Syria \\ ${ }^{\square}$ Corresponding Author: rassi.salwa@gmail.com; Tel.: +963-966-243-153 \\ Received: April 4, 2016; Revised: May 28, 2016; Accepted: May 29, 2016
}

\begin{abstract}
A construction and electrochemical behavior of novel potentiometric membrane sensor responsive to the etoricoxib was described. The sensor was based on the ion-pair complex of etoricoxib (ET) with uracil-5,6-diamino-2-thio hydrochloride (UDTH) (ETUDTH) as exchange sites in a PVC matrix with different plasticizers dioctyl phthalate (DOPH) (electrode A), dibutyl phthalate (DBPH) (electrode B), and tri-n-butyl phosphate (TBP) (electrode C). The electrodes exhibited near-Nernstian response for ET-UDTH over the concentration range 0.051-40.042 mM. The electrode offered significant advantages including long lifetime (about 2 months), excellent stability and reproducibility, good response time (10-25 s), and wide $\mathrm{pH}$ working range ( $\mathrm{pH}$ 5-12). Selectivity coefficients of $E T$ related to a number of interfering cations and some organic compounds were investigated, and there were negligible interference caused by most of the investigated species. The direct determination of 0.5-10 $\mathrm{mM}$ of ET showed an average recovery of 99.03-101.75 \% and a mean relative standard deviation 0.40-1.88. The results were obtained by determination of ET in tablets using the proposed electrodes which were comparable favorably with those obtained by spectrophotometric method.
\end{abstract}

\section{Keywords}

Etoricoxib, Uracil-5,6-diamino-2-thio hydrochloride, PVC membrane, Potentiometric method validation.

\section{Introduction}

Etoricoxib (5-chloro-6'-methyl-3-[4-(methylsulfonyl)phenyl]-2,3'-bipyridine) represents a second-generation of COX-2 inhibitors that has been developed for the treatment of many inflammatory diseases such as rheumatoid arthritis, osteoarthritis, pain relief and acute gout, 
causing fewer gastrointestinal complications than conventional non-steroidal anti-inlammatory drugs (NSAIDs) [1-2]. The potential use of this COX-2 inhibitor among the general public is high due to their improved safety profile over traditional NSAIDs. Traditional NSAIDs such as aspirin and ibuprofen, inhibit both the COX-1 and COX-2 enzymes [3]. The COX-1 enzyme, which is expressed in essentially all tissues, has been found to play a role in the homeostasis of the gastrointestinal tract and kidneys, while the COX-2 enzyme is absent unless induced by an inflammatory event. Consequently, side effects of chronic use of traditional NSAIDs include gastrointestinal ulceration and bleeding [4]. Etoricoxib, a highly selective COX-2 inhibitor, was developed in order to address the safety issues associated with traditional NSAIDs, while providing pain relief from inflammatory illness such as osteo- and rheumatoid arthritis [5].

In order to provide quality control over the manufacture of any active pharmaceutical ingredient, it is essential to develop highly selective analytical techniques. Therapeutic importance of etoricoxib has prompted the development of many methods for its assay. The drug is available in tablet dosage form and is not yet official in any of the pharmacopoeias. Several methods have been reported for the analysis of etoricoxib in pharmaceutical dosage form as well as in the biological fluids and tissues, such as spectrophotometric methods [6-8], chromatographic methods HPLC [9-12], high-performance thin-layer chromatography [13], LC/MS spectrophotometry [14-18] and RP-HPLC method $[6,19,20]$ for the estimation of etoricoxib.

\section{Experimental}

\section{Reagents}

All reagents used were of analytically pure grade and doubly distilled water was used throughout. High-molecular-weight poly(vinyl chloride) (PVC) was obtained from SABIC. Co., dioctyl phthalate $98.9 \%$ (DOPH), tri-n-butyl phosphate $97 \%$ (TBP), and di-n-butyl phthalate $99 \%$ (DBPH) were obtained from BDH. Co., England. Tetrahydrofuran (THF) was obtained from Merck. Pure-grade etoricoxib (99.95\%) $\left(\mathrm{C}_{18} \mathrm{H}_{15} \mathrm{Cl} \mathrm{N}_{2} \mathrm{O}_{2} \mathrm{~S}, 358.1 \mathrm{~g} \mathrm{~mole}^{-1}\right)$ was obtained from Aarti Drugs Limited (Indian). Uracil-5,6-diamino-2-thio hydrochloride (UDTH) $\left(\mathrm{C}_{4} \mathrm{H}_{7} \mathrm{~N}_{4} \mathrm{OSCl}, 194.5 \mathrm{~g}\right.$ mole $\left.{ }^{-1}\right)$ was synthesized (Figure 1) and identified in laboratory by spectroscopic means. The H-NMR and IR data (Figure 2) of UDTH are shown in Table 1.

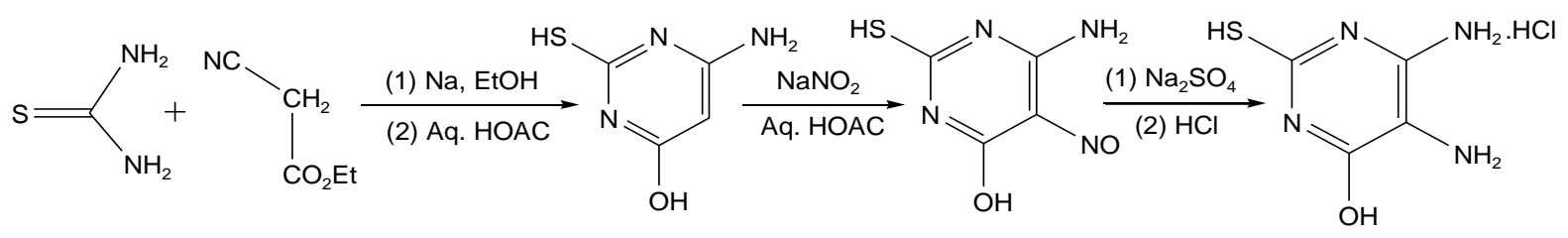

Figure 1. Synthesis of UDTH.

\section{Apparatus}

Potentiometric and $\mathrm{pH}$ measurements was carried out using a digital Shott Gerate $\mathrm{pH}$ meter (Consort C 830, Belgium) with combined glass $\mathrm{pH}$ electrode. A water bath shaker (Grant instruments, Cambridge Ltd, England) was used to control the temperature of the test solutions. A saturated calomel electrode (SCE) was used as the external reference (Mettler, Switzerland) while an $\mathrm{Ag} / \mathrm{AgCl}$ electrode was used as an internal reference. The electrochemical system may be represented as follows:

$\mathrm{Ag} / \mathrm{AgCl}$ | inner solution | PVC membrane | test solution || $\mathrm{KCl}$ salt bridge || $\mathrm{Hg} / \mathrm{HgCl}_{2}$ (sat.). 
FT-IR 4100 (Fourier Transform Infrared Spectrometer) Jasco using $\mathrm{KBr}$ disk in the range $4000-400 \mathrm{~cm}^{-1}$, Nernst glower, deuterium try glycine sulfate (DTGS), $0.1 \mathrm{~cm}^{-1}$.

\section{Preparation of solutions}

Standard ET solutions (0.05-35 mM) were prepared in doubly distilled water. UDTH solution (10 $\mathrm{mM}$ ) was prepared by dissolving appropriate amount of the compound in the methanol. ET and UDTH stock solutions were stored in dark bottle at refrigerator. Stock solutions of $1 \mathrm{M}$ for each of $\mathrm{LiCl}, \mathrm{NaCl}, \mathrm{KCl}, \mathrm{NH}_{4} \mathrm{Cl}, \mathrm{CaCl}_{2}, \mathrm{MgCl}_{2}, \mathrm{BaCl}_{2}, \mathrm{ZnCl}_{2}, \mathrm{MnSO}_{4}, \mathrm{Ni}\left(\mathrm{NO}_{3}\right)_{2}, \mathrm{Co}\left(\mathrm{NO}_{3}\right)_{2}, \mathrm{Cu}\left(\mathrm{NO}_{3}\right)_{2}$, $\mathrm{Pb}\left(\mathrm{NO}_{3}\right)_{2}, \mathrm{FeCl}_{3}, \mathrm{AlCl}_{3}, \mathrm{CrCl}_{3}$, glucose, fructose, lactose, starch, micro crystalline cellulose, carboxymethyl cellulose, polyethylene glycol, titanium dioxide, and polysorbate- 80 were prepared by dissolving the appropriate amount of the compounds, and the diluted solutions from these were prepared by subsequent dilutions of the stock solutions.

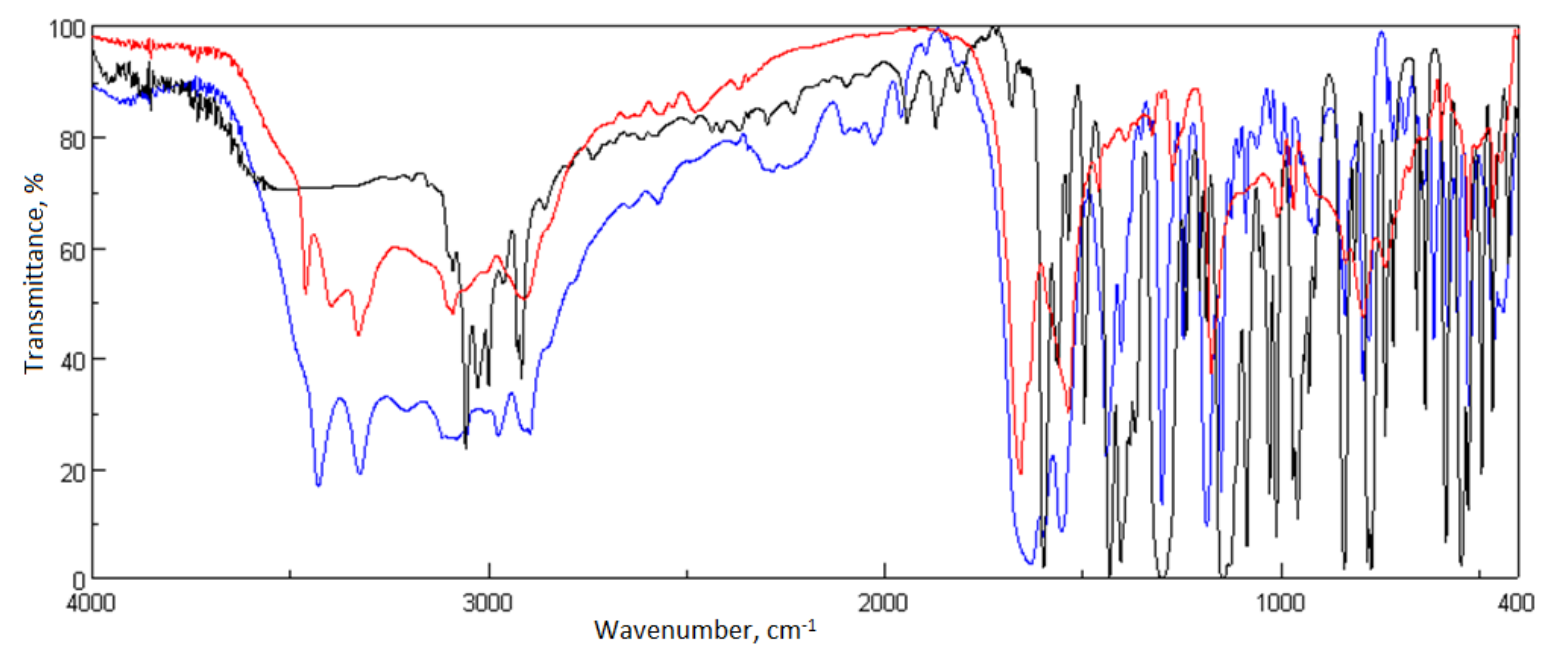

Figure 2. IR spectrum of etoricoxib (black spectrum), UDTH (red spectrum), and ET+UDTH- complex (blue spectrum)

\section{Sample Preparation}

Etoricoxib tablets were supplied by Razi Pharmaceutical Industries (Aleppo, Syria). Each tablet was labeled to contain etoricoxib $120,90,60 \mathrm{mg} / \mathrm{tab}$. The homogenized powder was prepared from ten accurately weighed ET tablets. An appropriate amount of this powder was dissolved in methanol and doubly distilled water. The mixture was then filtered and made up to the mark in a $100 \mathrm{~mL}$ volumetric flask. Different volumes of the stock solution were taken and subjected to the direct and standard addition methods.

\section{Preparation of ion-pair compound}

Ion-pair $\left(\mathrm{ET}^{+} \mathrm{UDTH} \mathrm{H}^{-}\right)$was prepared by mixing equal volumes of $10^{-2} \mathrm{M}$ methanolic solution of ET with methanolic solution of UDTH with stirring. Methanol was then gradually evaporated to obtain a precipitate. ${ }^{1} \mathrm{H}-\mathrm{NMR}$ and IR data (Figure 2 ) of $\mathrm{ET}^{+} \mathrm{UDTH}^{-}$are shown in Table 1.

\section{Construction of etoricoxib membrane electrodes}

The electrodes were constructed according to the method described by Craggs et al. [8]. Membrane composition was studied by varying the percentages (w/w) of the ion-pair complex, PVC and DOPH (electrode A), DBPH (electrode B), or TBP (electrode C) as plasticizing solvent mediators. The optimum composition that exhibited perfect performance characteristics was 
reached. The membranes were prepared by dissolving the required amounts of ion pair complex, PVC and DOPH, DBPH or TBP in THF, and then the homogeneous mixture was poured into glass Petri dishes ( $8 \mathrm{~cm}$ diameter), covered with a glass plate, and allowed to evaporate overnight at room temperature. The thickness of obtained membrane was about $0.15 \mathrm{~mm}$. Membranes (12 $\mathrm{mm}$ diameter) were cut out and then adhered to the polished end of a plastic cap attached to a glass tube using PVC-THF paste. The electrodes bodies were filled with a $1 \times 10^{-1} \mathrm{M} \mathrm{KCl}$ solution and $1 \times 10^{-3} \mathrm{M} \mathrm{ET}$ as the inner electrolyte, and then $\mathrm{Ag} / \mathrm{AgCl}$ was inserted in it as internal reference electrode. Electrode potential was measured against the SCE as the reference electrode. Before use, the electrode membranes were conditioned by immersion in $25 \mathrm{mM}$ of ET solution for $3 \mathrm{~h}$.

Table 1. H-NMR and IR data for UDTH and Complex between UDTH and ET.

\begin{tabular}{|c|c|c|c|c|c|}
\hline & \multicolumn{2}{|c|}{$\delta / \mathrm{ppm}$} & & \multicolumn{2}{|c|}{ Wavenumber, $\mathrm{cm}^{-1}$} \\
\hline & $\mathrm{ET}^{+} \mathrm{UDTH}^{-}$ & UDTH & & UDTH & $\mathrm{ET}^{+} \mathrm{UDTH}^{-}$ \\
\hline$-\mathrm{SH}$ & --- & 12.48 & $-\mathrm{SH}$ & 2479 & --- \\
\hline$-\mathrm{OH}$ & 11.53 & 11.55 & $-\mathrm{OH}$ & 3460 & 3440 \\
\hline$-\mathrm{NH}_{3}^{+}$ & 4.28 & 6.27 & $-\mathrm{NH}_{2}$ & $3328-3390$ & $3250-3325$ \\
\hline$-\mathrm{NH}_{2}$ & 7.74 & 8.00 & $\mathrm{~N}-\mathrm{S}$ & --- & 1186 \\
\hline$-\mathrm{CH}_{3}$ & 2.76 & & & & \\
\hline$-\mathrm{CH}_{3}$ & 3.25 & & & & \\
\hline $9 \mathrm{H}$ aromatic & $7.88-8.57$ & & & & \\
\hline
\end{tabular}

\section{Selectivity of sensors}

Potentiometric selectivity coefficient, $K_{A, B}^{\text {pot }}$, of an ion-selective electrode (ISE) was commonly used as quantitative expression of the ability of the electrode to respond primarily to the analyte in the presence of interfering ions. The effect of the presence of some different species on the response of ET electrodes was investigated, and the selectivity coefficient $K_{A, B}^{\text {pot }}$ of the proposed electrodes was calculated in the presence of related organic and inorganic substances using matched potential method (MPM) [9-10]. The selectivity coefficient, $K_{\mathrm{A}, \mathrm{B}}^{\mathrm{pot}}$, which was measured by matched potential method was calculated according to the following equation:

$$
K_{\mathrm{A}, \mathrm{B}}^{\mathrm{MPM}}=\frac{\left(a_{\mathrm{A}}^{\prime}-a_{\mathrm{A}}\right)}{a_{\mathrm{B}}}
$$

where $a_{\mathrm{A}}^{\prime}$ is the known activity of primary ion, $a_{\mathrm{A}}$ is the fixed activity of primary ion, and $a_{\mathrm{B}}$ is the activity of interfering ions.

\section{General procedures}

The performance of the three electrodes prepared was investigated by measuring e.m.f. values of 0.05-45 mM of ET. The electrodes were calibrated by added volumes of $50 \mathrm{mM}$ stock solution of ET successively in $50 \mathrm{ml}$ of water to generate a total concentration ranging from 0.05 to $45 \mathrm{mM} \mathrm{ET}$, followed by immersing the ET-electrode, together with a SCE in the solution. The potential reading was recorded after stabilization, and the e.m.f was plotted as a function of the logarithm of the ET concentration. The concentration graph was used for subsequent determinations of unknown ET concentrations. The e.m.f. measurements with the polymeric membrane electrodes were carried out with the cell assembly shown schematically in the section 2.2. 


\section{Potentiometric determination of ET}

ET was determined potentionmetrically by the direct and standard addition methods [11-12]. In this method the proposed electrodes (A,B) (ET-UDTH) were immersed into a sample of $15 \mathrm{ml}$ with an unknown concentration of a ET solution, and the equilibrium potential, $E_{\mathrm{u}}$, was recorded. Then $1 \mathrm{ml}$ of $50 \mathrm{mM}$ of standard ET was added into the testing solution and the equilibrium potential, $E_{\mathrm{s}}$, was obtained. From the potential change, $\Delta E=E_{\mathrm{u}}-E_{\mathrm{s}}$, we could determine the concentration of the testing sample using the equation:

$$
C_{x}=\frac{C_{s} V_{s}}{\left(V_{x}+V_{s}\right) \times 10^{\Delta E / S}-V_{x}}
$$

where $C_{\mathrm{x}}$ and $V_{\mathrm{x}}$ are concentration and volume of an unknown sample, $C_{\mathrm{s}}$ and $V_{\mathrm{s}}$ are concentration and volume of the standard, respectively. $S$ is the slope of the calibration graph (slope of the electrode response), and $\Delta E$ is the difference in $(\mathrm{mV})$ between e.m.f. after and before addition of the standard solution. Standard addition method was applied for determining ET in commercial preparations.

\section{Results and discussion}

\section{Optimization of the membrane composition}

The effect of the amount of ion pair in the membrane phase on the potentiometric response was investigated. The data shown in Table 2 clearly indicate that the electrode (V) with 5 wt\% of ET-UDTH ion pair has performance characteristics (slope $57.00 \mathrm{mV}$ decade ${ }^{-1}$, at $25^{\circ} \mathrm{C}$, usable concentration range, 0.031-40.042 $\mathrm{mM} \mathrm{ET}$ ), and response time $25 \mathrm{~s}$. For all construted electrodes, the percentage of ion-pair ranging from 1 to $8 \%$ was found to offer better slopes and correlation coefficients. The results obtained with ion-pair for the three plasticizers are summarized in Table 2. The electrodes $A$ and $B$ exhibit comparable linear ranges and the lowest detection limit.

Table 2. Optimization of the membrane ingredients.

\begin{tabular}{|c|c|c|c|c|c|}
\hline \multicolumn{4}{|c|}{ Composition, \% (w/w) } & \multirow{2}{*}{ Slope, mV decade- ${ }^{1}$} & \multirow{2}{*}{ Detection limit, mM } \\
\hline Membrane & Ion-pair Complex & PVC & DBPH & & \\
\hline 1 & 1 & 49.5 & 49.5 & 48.62 & 0.39 \\
\hline II & 2 & 49.0 & 49.0 & 50.24 & 0.31 \\
\hline III & 3 & 48.5 & 48.5 & 53.14 & 0.25 \\
\hline IV & 4 & 48.0 & 48.0 & 55.69 & 0.19 \\
\hline $\mathbf{V}$ & 5 & 47.5 & 47.5 & $\mathbf{5 7 . 0 0}$ & 0.13 \\
\hline VI & 6 & 47.0 & 47.0 & 54.06 & 0.25 \\
\hline VII & 7 & 46.5 & 46.5 & 52.09 & 0.20 \\
\hline VIII & 8 & 46.0 & 46.0 & 49.51 & 0.34 \\
\hline
\end{tabular}

\section{Effect of the internal filling solution}

The concentration of the internal solution of ET in the electrode was changed from 10 to $0.01 \mathrm{mM}$ and the potential response of the electrode was measured. It was found that variation of the concentration of the internal solution did not cause any significant difference in the potential response of the electrode. ET concentration of $1 \mathrm{mM}$ as internal solution was quite appropriate for proper functioning of the electrode. 


\section{Effect of plasticizer type on the characteristic performance of the sensor}

Three plasticizers, DOPH, DBPH and TBP were evaluated. As shown in Table 3, the best performances, in terms of slopes, linear range and detection limit obtained had the following order: DBP (electrode B) > DOPH (electrode A) > TBPH (electrode C). The working characteristics for the electrodes were assessed on the basis of their calibration curves. The TBP which had a low viscosity $(3.11 \mathrm{cSt}$ ), led to leaching of the complex from the membrane. All further studies were conducted using DBPH and DOPH as plasticizers.

Table 3. Effect of the nature of an ion-pair and a plasticizer on characteristics of the electrodes.

\begin{tabular}{|c|c|c|c|}
\hline Electrode & A & B & C \\
\hline Ion-pair complex, wt \% & 5 & 5 & 7 \\
\hline Plasticizer & DOPH & DBPH & TBP \\
\hline Slope, mV decade ${ }^{-1}$ & 56.26 & 57.00 & 41.23 \\
\hline Linear range, $\mathrm{mM}$ & $0.051-39.810$ & $0.031-40.042$ & $0.653-33.140$ \\
\hline Correlation coefficient & 0.9997 & 0.9999 & 0.9699 \\
\hline Detection limit, mM & 0.042 & 0.023 & 0.324 \\
\hline
\end{tabular}

\section{Effect of soaking}

Freshly prepared electrodes must be soaked to activate the surface of the membrane to form an infinitesimally thin layer for ion-exchange process to occur [13]. This preconditioning process required different times, depending on the diffusion of ions and their equilibrium at the electrode test solution interface. Fast establishment of equilibrium was certainly a condition for a fast potential response. Thus, the performance characteristic of the ET electrode was investigated as a function of the soaking time. For this purpose the electrode was soaked in a $50 \mathrm{mM}$ solution of ET, UDTH and water at room temperature. The optimum soaking time and the optimum solution was found to be $3 \mathrm{~h}$ for $50 \mathrm{mM}$ solution of ET. During this period sensors were washed with water after each application and kept dry in air at room temperature when off-use. The results indicate that for a time of $3 \mathrm{~h}$ of soaking the slope remained constant at about $57.00 \mathrm{mV}$ decade ${ }^{-1}$, at $25^{\circ} \mathrm{C}$. $E$, $\mathrm{mV}$ vs. $t$, min plots (Fig. 3) were obtained after the electrode was soaked continuously in $50 \mathrm{mM}$ ET, water and UDTH for 30-630 min.

\section{Effect of $\mathrm{pH}$}

The influence of the $\mathrm{pH}$ on the potentiometric responses of membrane electrodes was investigated by following the potential variation over the $\mathrm{pH}$ range of 1-14. The electrode response for different ET concentration was tested at various $\mathrm{pH}$ values. The $\mathrm{pH}$ of the solution was adjusted by adding small volumes of hydrochloric acid or sodium hydroxide to the test solution. As can be seen from Figure 4, membrane electrode exhibited a negligible potential change within the $\mathrm{pH}$ range of $5-12$. At lower $\mathrm{pHs}(\mathrm{pH}<6)$ there was a decrease in potential which may be due to the interference of hydronium ion and the penetration of $\mathrm{H}_{3} \mathrm{O}^{+}$into the membrane surface, or a gradual increase of the protonated species [14-15].

\section{Effect of the temperature of the test solution}

The effect of the temperature of the test solution on the potential response of the membrane was tested by following the slopes variation in the temperature range $20-65^{\circ} \mathrm{C}$ (Fig. 5). The results show that within the temperature range investigated the electrodes respond practically to the ET concentration with slopes from 54.23 to $57.30 \mathrm{mV}$ decade ${ }^{-1}$ and usable concentration range of about 0.031-40.042 $\mathrm{mM}$. 


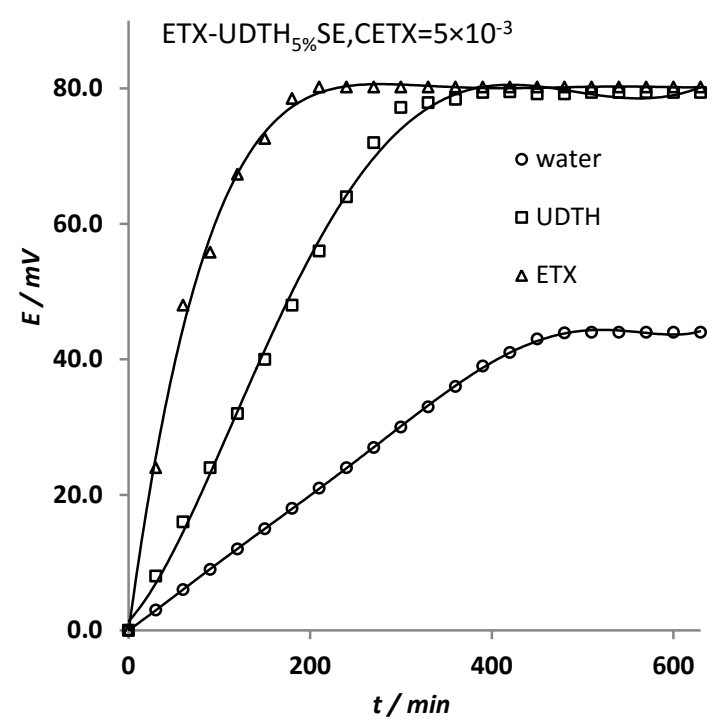

Figure 3. Effect of stock solution on response electrode

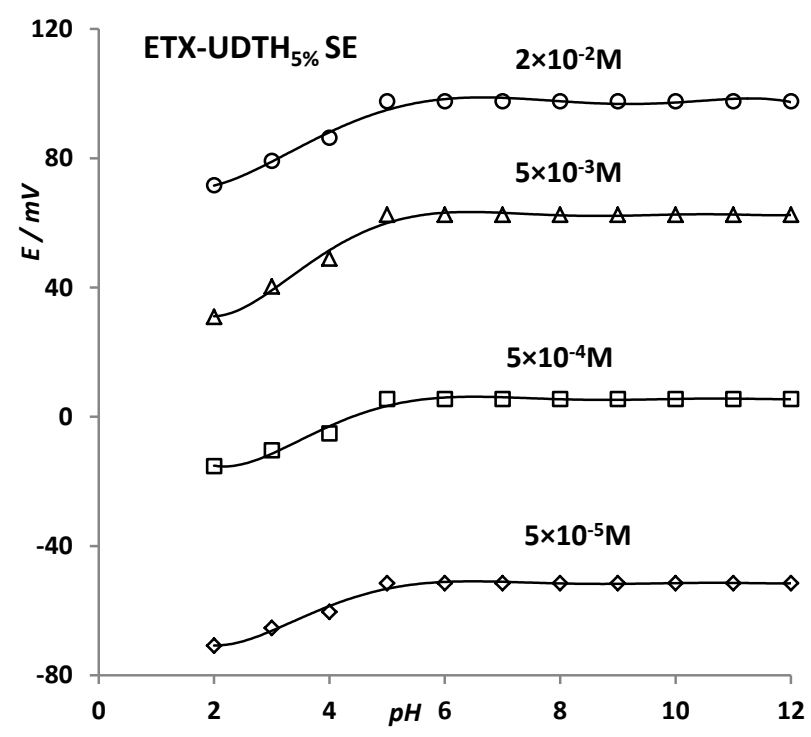

Figure 4. Effect of the $\mathrm{pH}$ on the response of the electrode

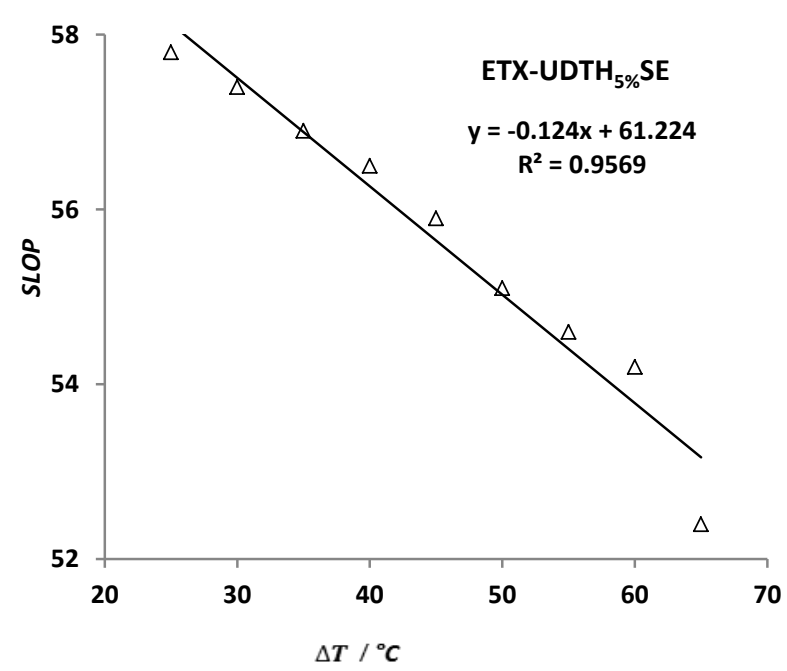

Figure 5. Effect of the temperature of the test solution on the potential response of the membrane. 


\section{Calibration graphs}

Using the optimized membrane composition and conditions described above, the potentiometric response of the electrode was studied based on the ET concentration in the range of 0.01- $50 \mathrm{mM}$. The calibration curves for the electrodes A and B containing DOP or DBP as plasticizer gave an excellent linear response from 0.031 to $40.042 \mathrm{mM}$, as shown in Figure 6. The results given in Table 3 show the characteristics performance of the membrane electrodes. The least squares equation obtained from the calibration data was as follows:

$$
E / m V=S \times \log ([E T, M])+\text { intercept }
$$

where $E$ is the potential and $S$ the slope of the electrodes.
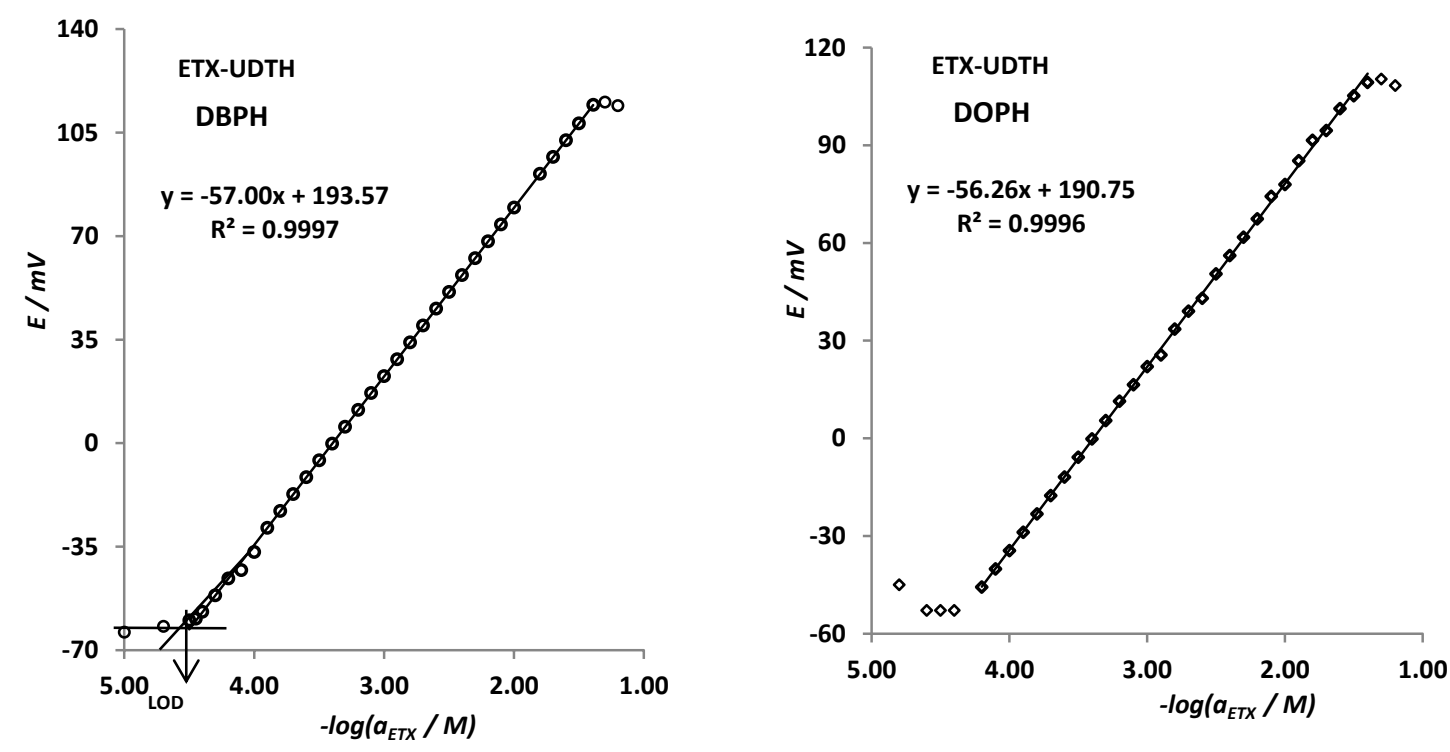

Figure 6. Calibration graph of ET membrane electrode.

Table 4. Response characteristics of membrane electrodes

\begin{tabular}{|l|c|c|}
\hline Electrode number & A & B \\
\hline Plasticizer & DOPH & DBPH \\
\hline Parameter & \multicolumn{2}{|c|}{} \\
\hline Slope, $\mathbf{m V} /$ decade $^{-1}$ & 56.26 & 57.00 \\
\hline Correlation cofficient & 0.9996 & 0.9997 \\
\hline Linearity range, $\mathbf{m M}$ & $0.051-39.810$ & $0.031-40.042$ \\
\hline Lower detection limit, $\mathbf{m M}$ & 0.042 & 0.023 \\
\hline Response time, $\mathbf{s}$ & $\mathrm{t} \leq 35$ & $\mathrm{t} \leq 25$ \\
\hline Working $\mathbf{p H}$ range & $5.0-12.0$ & $5.0-12.0$ \\
\hline Temperature, $^{\circ} \mathbf{C}$ & 25 & 25 \\
\hline Life time, days & 44 & 55 \\
\hline
\end{tabular}

\section{Response time}

The time required for the electrodes to reach steady potential values, after immersing the electrode in different concentration namely from $0.05,0.5,5$ and $25 \mathrm{mM}$ of ET solution was studied. The average time was found to be short, ranging from $10 \mathrm{~s}$ for concentrations $25 \mathrm{mM}$ and $5 \mathrm{mM}$, to about $25 \mathrm{~s}$ for $0.05 \mathrm{mM}$ solution. Two electrodes gave the same range of response times. These values indicated the high stability of the electrodes during the measurements. A typical plot for response time is shown in Fig. 7 for the electrode based on DBP as the plasticizer. 


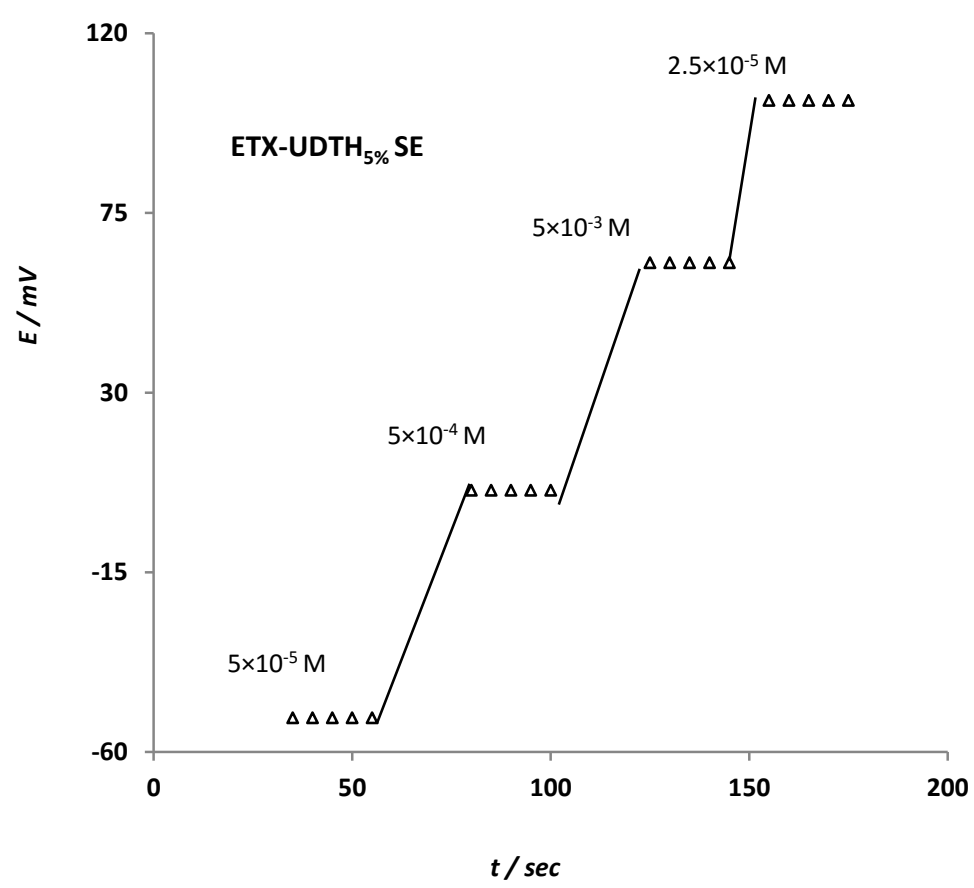

Figure 7. Plot the response time of DBP electrode using 0.05, 0.5, 5, $25 \mathrm{mM}$ etoricoxib.

\section{Lifetime}

The electrode lifetime was investigated by performing the calibration curve and the periodic testing of standard solutions (0.031-40.042 mM of ET) and calculating the response slope. It was observed that the electrode B exhibited good stability in terms of slope in the linear domain of concentration and the electrodes could be used continuously for about 55 days without considerable decrease in its slope value. Electrode $A$ exhibited good stability in terms of slopes of 56.20 to $53.4 \mathrm{mV}$ decade $^{-1}$ in the linear domain of concentration from 0.051 to $39.810 \mathrm{mM}$. This electrode could be used continuously for about 44 days. But two changes were observed, firstly, a slight gradual decrease in the slope (from 57.00 to $55.23 \mathrm{mV}$ decade ${ }^{-1}$ ) was found, and secondly an increase in the detection limit (from 0.023 to $0.2 \mathrm{mM}$ ) was noted. However, the electrode with DBP as plasticizers could be used for about 55 days without any considerable decrease in the slope value.

\section{Selectivity of electrode}

The influence of some inorganic cations such as of $\mathrm{Li}^{+}, \mathrm{Na}^{+}, \mathrm{K}^{+}, \mathrm{Ca}^{2+} \mathrm{Zn}^{2+}, \mathrm{Ba}^{2+}, \mathrm{Mn}^{2+}, \mathrm{Mg}^{2+}, \mathrm{Ni}^{2+}$, $\mathrm{NH}_{4}^{+}, \mathrm{Cu}^{2+} \mathrm{pb}^{2+}, \mathrm{CO}^{2+}, \mathrm{Fe}^{3+}, \mathrm{Al}^{3+}, \mathrm{Cr}^{3+}$, and some organic compound like sugars (glucose, fructose) and excipients on the electrode response was investigated. The selectivity of the electrode was measured by applying the matched potential method (MPM). According to this method, the activity of ET was increased from $a_{\mathrm{A}}=1 \mathrm{mM}$ (reference solution) to $a_{\mathrm{A}}^{\prime}=1.1 \mathrm{mM}$, and the changes in potential $(\Delta E)$ corresponding to this increase were measured. Then a solution of an interfering ion of concentration $a_{\mathrm{B}}$ is added to a new $1 \mathrm{mM}$ reference solution until the same potential change $(\Delta E)$ was recorded. The selectivity factor, $K_{A, B}^{\text {pot }}$, for each interference was calculated using equation (1). The results are given in Table 5 . Results revealed reasonable selectivity for ET in presence of many related substances. The selectivity coefficient obtained by this method showed that there were no significant interferences from the cations, this reflected a very high selectivity of the investigated electrode towards ET. 
Table 5. Selectivity coefficients for of the ET-UDTH responsive electrode.

\begin{tabular}{llcc}
\hline$K_{\mathrm{A}, \mathrm{B}}^{\mathrm{MPM}}$ & Interferent & $K_{\mathrm{A}, \mathrm{B}}^{\mathrm{MPM}}$ & Interferent \\
\hline $9.9 \times 10^{-5}$ & Glucose & $1.00 \times 10^{-4}$ & $\mathrm{Li}^{+1}$ \\
$2.0 \times 10^{-5}$ & Fructose & $1.25 \times 10^{-4}$ & $\mathrm{~K}^{+1}$ \\
$2.5 \times 10^{-5}$ & Lactose & $9.09 \times 10^{-5}$ & $\mathrm{Na}^{+1}$ \\
$4.3 \times 10^{-5}$ & starch & $5.56 \times 10^{-5}$ & $\mathrm{NH}^{+}$ \\
$8.0 \times 10^{-4}$ & Microcrestaline cellulose & $6.25 \times 10^{-5}$ & $\mathrm{Mg}^{+2}$ \\
$1.2 \times 10^{-5}$ & Carboxymetyle cellulose & $6.45 \times 10^{-5}$ & $\mathrm{Mn}^{+2}$ \\
$6.2 \times 10^{-6}$ & polyethylene glycol & $1.10 \times 10^{-5}$ & $\mathrm{Ca}^{+2}$ \\
$4.8 \times 10^{-5}$ & titanium dioxide & $7.14 \times 10^{-5}$ & $\mathrm{Ba}^{+2}$ \\
$8.6 \times 10^{-6}$ & polysorbate 80 & $5.13 \times 10^{-5}$ & $\mathrm{Ni}^{+2}$ \\
& & $5.81 \times 10^{-5}$ & $\mathrm{Cu}^{+2}$ \\
& & $7.69 \times 10^{-5}$ & $\mathrm{Zn}^{+2}$ \\
& & $9.52 \times 10^{-5}$ & $\mathrm{pb}^{+2}$ \\
& & $7.81 \times 10^{-5}$ & $\mathrm{Cd}^{+2}$ \\
& & $6.76 \times 10^{-5}$ & $\mathrm{Cr}^{+3}$ \\
& & $1.22 \times 10^{-5}$ & $\mathrm{Fe}^{+3}$ \\
\hline
\end{tabular}

Even though, the inorganic cations have different ionic sizes, mobilities and permeabilities they did not interfere with ET. The selectivity of the electrode towards neutral sugars was evaluated. The tolerance was considered as the concentration imparting a $\pm 0.2 \mathrm{mV}$ drift in the potential reading. The results indicated that glucose, fructose, lactose and starch did not interfere. The experiments showed no interference with respect to ET response for electrodes $A$ and $B$.

\section{Analytical application}

The ET membrane electrodes were used for the determination of ET in pharmaceutical preparations using both direct and standard-addition methods. The direct method is the simplest for obtaining quantitative results. A calibration graph was constructed and concentration of the unknown was calculated from the linear equation of the calibration curve. Direct determination of ET in tablets was carried out using the developed membrane electrodes. The results are summarized in Table 6 and 7.

Table 6. Accuracy and precision for the determination of ET using the proposed $P V C$ membrane sensors in pure solution

\begin{tabular}{|c|c|c|c|c|c|c|c|c|c|}
\hline \multirow[b]{2}{*}{ Electrode } & \multirow[b]{2}{*}{ Taken, mM } & \multicolumn{4}{|c|}{ Direct mothed } & \multicolumn{4}{|c|}{ Standard-addition method } \\
\hline & & Found, $\mathrm{mM}$ & RSD, \% & $R / \%$ & ASE & Found, $\mathrm{mM}$ & RSD, $\%$ & $R / \%$ & ASE \\
\hline \multirow{4}{*}{ A } & 0.5 & 0.50 & 1.88 & 100.00 & 0.005 & 0.49 & 2.13 & 98.00 & 0.007 \\
\hline & 2.5 & 2.49 & 1.80 & 99.60 & 0.026 & 2.44 & 1.97 & 97.60 & 0.034 \\
\hline & 5 & 4.95 & 1.45 & 99.00 & 0.042 & 5.08 & 1.74 & 101.60 & 0.063 \\
\hline & 10 & 9.95 & 0.86 & 99.50 & 0.050 & 9.94 & 1.56 & 99.40 & 0.110 \\
\hline \multirow{4}{*}{ B } & 0.5 & 0.49 & 1.52 & 98.00 & 0.004 & 0.51 & 1.46 & 102.00 & 0.005 \\
\hline & 2.5 & 2.54 & 1.24 & 101.70 & 0.018 & 2.53 & 1.32 & 101.20 & 0.024 \\
\hline & 5 & 4.98 & 0.81 & 99.60 & 0.023 & 4.98 & 1.01 & 99.60 & 0.036 \\
\hline & 10 & 10.06 & 0.62 & 100.60 & 0.035 & 10.19 & 0.91 & 101.90 & 0.068 \\
\hline
\end{tabular}

Average of four determinations

The content of drug in its formulation had good agreement with the declared amount. The standard-addition method was applied by adding a small portion $(1 \mathrm{~mL})$ of a $50 \mathrm{mM}$ standard ET solution to $15 \mathrm{~mL}$ of various formulation drug concentrations $(60,90,120) \mathrm{mg} \mathrm{ET} / \mathrm{tablet},(0.167$, 
$0.251,0.335) \mathrm{mM}$. The change in the potential reading (at a constant temperature of $25^{\circ} \mathrm{C}$ ) was recorded after each addition, and was used to calculate the concentration of ET by the equation (2). Thus, the determination of the concentration depended mainly on $\Delta E$, hence, to obtain a noticeable $\Delta E$ we needed to prepare a higher concentration of the ET standard. Results of the standard-addition method are given in Table 7.

The determination of ET in tablet was carried out using the proposed electrode. The results were compared to those obtained using the spectrophotometric method [16]. The determination of ET in its pharmaceutical formulations Etoxia gave an average Recovery of (100.06-100.75). Mean values were obtained with a Student's t- and F-tests at $95 \%$ confidence limits for four degrees of freedom are shown in Table 7. The data reveal that results compare favorably with those obtained by spectrophotometric. The results showed comparable accuracy ( $t$-test) and precision (F-test).

Table 7. Determination of ET in its pharmaceutical preparation using the proposed electrode.

\begin{tabular}{|c|c|c|c|c|}
\hline \multirow{2}{*}{ Sample } & \multirow{2}{*}{$\begin{array}{c}\text { Nominal value } \\
\mathrm{mgET} / \text { tablet } \\
\end{array}$} & \multicolumn{2}{|c|}{ Potentiometry } & \multirow[t]{2}{*}{ Spectrophotometry } \\
\hline & & Direct & Standard addition & \\
\hline Etoxia & 60 & & & \\
\hline$R / \% \pm \mathrm{SD}^{\mathrm{a}}$ & & $100.75 \pm 0.58$ & $100.47 \pm 0.61$ & $99.73 \pm 0.31$ \\
\hline$t$-Value ${ }^{b}$ & & 1.85 & 1.72 & 1.830 \\
\hline F-Value $^{\text {b }}$ & & 3.50 & 3.87 & \\
\hline Etoxia & 90 & & & \\
\hline$R / \% \pm \mathrm{SD}^{\mathrm{a}}$ & & $100.29 \pm 0.49$ & $100.43 \pm 0.54$ & $100.08 \pm 0.33$ \\
\hline$t$-Value ${ }^{b}$ & & 1.32 & 2.15 & 0.57 \\
\hline F-Value ${ }^{\text {b }}$ & & 2.20 & 1.86 & \\
\hline Etoxia & 120 & & & \\
\hline$R / \% \pm S D^{a}$ & & $100.06 \pm 0.23$ & $100.46 \pm 0.55$ & $100.46 \pm 0.49$ \\
\hline$t$-Value ${ }^{b}$ & & 1.89 & 0.58 & 2.05 \\
\hline F-Value $^{b}$ & & 1.26 & 4.53 & \\
\hline
\end{tabular}

a Five independent analyses.

$b$ Theoretical values for $t-$ and $F$-values at four degree of freedom and 95\% confidence limit are $(t=2.776)$ and $(F=6.26)$.

\section{Conclusions}

In conclusion, the developed PVC membrane sensors described in this work offer a simple, accurate, selective, and specific tool for quantitative determination of ET in some pharmaceutical formulations. The membrane sensor ET-UDTH based on DBPH, seem to be better than ET-UDTH based on DOPH with respect to calibration, slop, and accuracy. The statistical evaluations of the proposed method in comparison with spectrophotometric method indicate that the method is accurate and precise. The proposed analytical method is proved to be simple and rapid, with good accuracy.

\section{References}

[1] D. Riendeau., M.D. Percival, C. Brideau, S. Charleson, D. Dube, D. Ethier, J.-P. Falgueyret, , R.W. Friesen, R. Gordon, G. Greig, J. Guay, J. Mancini, M. Ouellet, E. Wong, L. Xu, S. Boyce, D. Visco, Y. Girard, P. Prasit, R. Zamboni, I.W. Rodger, M. Gresser, A.W. Ford-Hutchinson, R.N. Young, C.-C. Chan, J. Pharmacol. Exp. Ther. 296(2) (2001) 558-566.

[2] A.D. Rodrigues, R.A. Halpin, L.A. Geer, D. Cui, E.J. Woolf, C.Z. Matthews, K.M. Gottesdiener, P.J. Larson, K.C. Lasseter, N.G.B. Agrawal, Drug Metab. Dispos. 31 (2) (2003) 224-232.

[3] B. Cryer, M. Feldman, Am. J. Med. 104 (1998) 413-421. 
[4] M.C. Allison, A.G. Howatson, C.J. Torrance, F.D. Lee, R.I. Russell, New Engl. J. Med. 327 (1992) 749-754.

[5] R.W. Friesen, C. Brideau, C. Chan, S. Charleson, D. Deschenes, D. Dube, D. Ethier, R. Fortin, J. Gauthier, Y. Girard, R. Gordon, G.M. Greig, D. Reindeau, C. Savoje, Z. Wang, E. Wong, D. Visco, J. Xu, R.N. Young, Bioorg. Med. Lett. 8 (1998) 2777-2782.

[6] R.M. Singh, Y. Kumar, D.K. Sharma, S.C. Mathur, G.N. Singh, T.A. Ansari, S. Jamil, Indian. Drugs 42(8) (2005) 535-536.

[7] B.N. Suhagia, H.M. Patel, S.A. Shah, I.S. Rathod, B.P. Marolia, Indian J. Pharm. Sci. 67(5) (2005) 634-637.

[8] A. Craggs, G.J. Moody, J.D.R. Thomas, J. Chem .Edu. 51 (1974) 541-544.

[9] Y. Umezawa, K. Umezawa, H. Sato, Pure. Appl. Chem. 67(3) (1995) 507-518.

[10] Y. Umezawa, Ph.B. HImann, K. Umezawa, K. Tohda, Sh. Amemiya, Pure. Appl. Chem. 72 (2000) 1851-2082.

[11] E. Baumann, Anal. Chem. Acta 42 (1968) 127-132.

[12] S. TNVSS, D Aditya, T. Santosh, B. S. Sundar, IAJPR 3(4)(2013) 3044-3056.

[13] D. G. Peters, J. M. Hayes, G. M. Hieftje, Chemical Separations and Measurements. W.B. Saunders, Philadelphia, 1974, pp 835.

[14] Y. M. Issa, M. M. Hassouna, F. M. Abdel-Gawad, E. M. Hussien, J. Pharm. Biomed. Anal. 23(2-3) (2000) 493-502.

[15] R. I. Stefan, H. Y. Aboul-Enein, G. E. Baiulescu, Sens. Actuators B 37 (1996) 141-144.

[16] M. Arvand, M. Vejdani, M. Moghimi, Desalination 225 (2008) 176-184.

[17] K. Shah, A. Gupta, P. Mishra, J. Chem 6(1) (2009) 207-212.

[18] P.G. Sunitha, N. Deattu, R. Ravi Kumar, S. Sri Rudhra, P. Kalaimathi, B. Soundiramani, A.C.M.S (1) (2015) 36-38.

[19] R. Chandra, A. Sanghi, D. Kumar, K.K. Hindwan, British Biomedical Bulletin 2 (4) (2014) 706714.

[20] S. Gholve, O. Bhusnure, O. Mathew1and J. Sangshet, Int. J. Pharm. Bio. Sci. 7(2) (2016) 246253.

(c) 2016 by the authors; licensee IAPC, Zagreb, Croatia. This article is an open-access article distributed under the terms and conditions of the Creative Commons Attribution license (http://creativecommons.org/licenses/by/4.0/) 